\title{
Membrane Based Enthalpy Heat Exchanger Performance in HVAC System
}

\author{
M. S. Nasif ${ }^{1 *}$, G. L. Morrison ${ }^{2} \&$ M. Behnia ${ }^{3}$ \\ ${ }^{1,2 \& 3}$ School of Mechanical and Manufacturing Engineering, University of New South Wales \\ Sydney NSW 2052, Australia
}

\begin{abstract}
The performance of a membrane based heat exchanger utilizing porous paper as the heat and moisture transfer media used in ventilation energy recovery systems is presented. A mathematical model was developed and validated against the experimental results. This model can be used for design aide to predict the effectiveness of the heat exchanger. Furthermore, system analysis of an air conditioner shows an increase in the coefficient of performance and cooling capacity when paper heat exchanger is used, especially in a climate similar to the weather in Malaysia and Darwin.
\end{abstract}

Keywords : Membrane based heat exchanger, ventilation energy recovery systems

\subsection{INTRODUCTION}

In the last few decades, many countries have adopted new standards for building ventilation that specify higher outdoor ventilation due to concerns over indoor air quality, which is affected by volatile organic compounds, smoke, dust and bacteria. Thus, more energy is required to condition the outdoor air where, the air conditioning load constitutes 20 to $40 \%$ of the thermal load for commercial buildings [1] and it can be even higher when 100\% fresh air is used. Due to energy conservation demands, energy recovery systems are used which can recover a large fraction of this load. This can be achieved by utilizing the room exhaust air to pre-cool or heat the fresh air before it enters the air conditioning system. This will save a large fraction of energy which in return will reduce the HVAC required operating cost. In the past, devices such as sensible heat exchange wheels and plate heat exchangers have been used in energy recovery systems [2]. These devices could transfer sensible heat only, neglecting latent heat recovery. These devices have limitations, such as condensation and suffer from corrosion if plate heat exchangers are used. This led to an increased attention on energy recovery systems to recover both latent and sensible energy. In order to recover sensible energy, heat needs to be transferred and in order to recover latent energy, moisture needs to be transferred. Heat and mass transfer are in fact analogous to each other and whenever there is a gradient in heat or mass

\footnotetext{
* Correspondence: Mohamad Shakir Nasif (Tel: +61 29385 5127, Fax: +61 29663 1222, Email: m.nasif@student.unsw.edu.au)
} 
concentration, heat and mass will be transferred from the hot and higher concentration side to the colder and lower concentration side. This phenomenon is used in ventilation energy recovery systems, where the ambient hot and humid supply air is passed over one side of a membrane heat exchanger and in the other stream, the room exhaust air is passed, which is cold and less humid. Due to the gradient in the heat and moisture concentration, heat and moisture are transferred across the membrane surface, causing a decrease in temperature and humidity of the supply air stream before it enters the evaporator unit, hence both sensible and latent energy are recovered. Zhang and Jiang [3] investigated the performance of such systems and for simplicity they used a cross flow heat exchanger. They investigated the improvement of the energy recovery ventilator effectiveness using different types of membranes and different airflow arrangements. Their results show that the highest sensible and latent effectiveness occurred when the counter flow heat exchanger is used. However, in a real application of a heat exchanger, it is difficult to implement a counter flow arrangement as both inlet and outlet ducts are located on the same side of the heat exchanger.

The aim of the work is to evaluate experimentally the performance of a $\mathrm{Z}$ type flow air-to-air heat exchanger (Figure 1) using 45 gsm paper as the heat and moisture transfer surface and to develop mathematical models for design aide. This $\mathrm{Z}$ flow configuration will provide a counter flow arrangement. Therefore, heat and moisture transfer will improve relative to the counter flow arrangement over a substantial part of the heat exchanger surface. As a result, the amount of energy recovered will increase relative to the cross configuration investigated by Zhang and Jiang [3]. In addition, system analysis will be performed to study the effect of utilizing paper heat exchanger on the performance and cooling capacity of an air conditioning system.

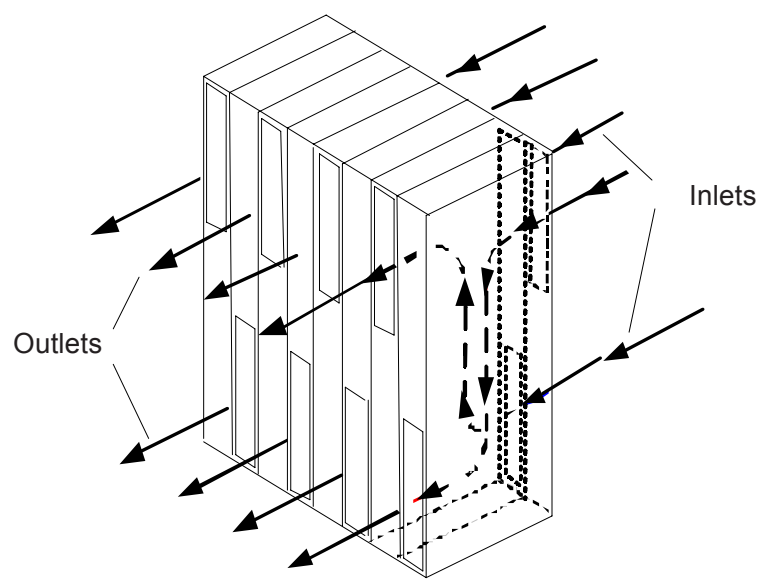

Figure $1 \mathrm{Z}$ type flow heat exchanger

\subsection{EFFECTIVENESS CALCULATION}

Heat exchanger effectiveness was calculated using Figure 2 and Equations (1) to (3) [4]:

Sensible effectiveness:

$$
\varepsilon_{S}=\frac{\dot{m}_{S} C p\left(T_{h i}-T_{h o}\right)+\dot{m}_{e} C p\left(T_{c o}-T_{c i}\right)}{2 \dot{m}_{\min } C p\left(T_{h i}-T_{c i}\right)}
$$


Latent effectiveness:

$$
\varepsilon_{L}=\frac{\dot{m}_{s} h_{f g}\left(\omega_{h i}-\omega_{h o}\right)+\dot{m}_{e} h_{f g}\left(\omega_{c o}-\omega_{c i}\right)}{2 \dot{m}_{\min } h_{f g}\left(\omega_{h i}-\omega_{c i}\right)}
$$

Total effectiveness:

$$
\varepsilon_{t o t}=\frac{\dot{m}_{s}\left(H_{h i}-H_{h o}\right)+\dot{m}_{e}\left(H_{c o}-H_{c i}\right)}{2 \dot{m}_{\min }\left(H_{h i}-H_{c i}\right)}
$$

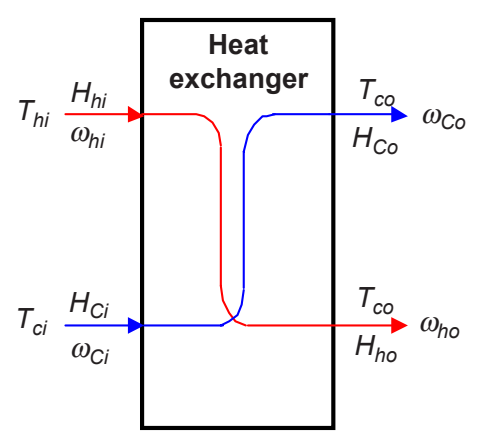

Figure 2 Heat exchanger schematic diagram

\subsection{HEAT EXCHANGER EXPERIMENTAL RIG}

The experimental rig consists of two separate air ducts arranged in parallel (Figure 3). At the duct entry, two centrifugal fans are mounted to supply variable airflow. In the hot air stream, steam is injected and air is heated. As for the cold air stream, air is supplied at ambient temperature. The performance is evaluated by calculating the sensible, latent and total effectiveness of the heat exchanger, through flow rate, humidity and wet and dry bulb temperature measurements at the

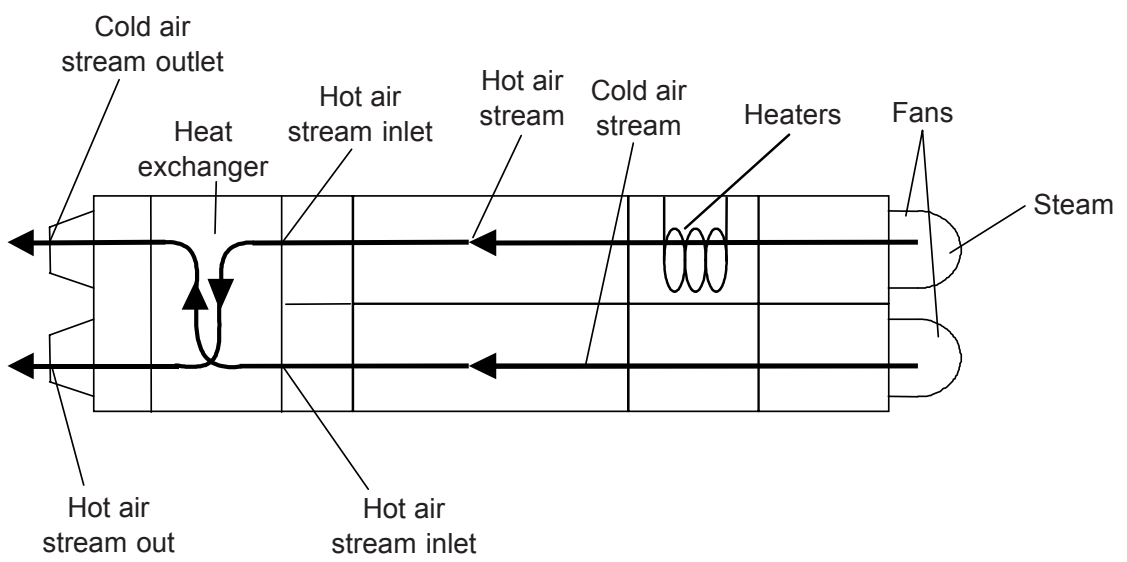

Figure 3 Experimental rig for testing $\mathrm{Z}$ flow heat exchanger 


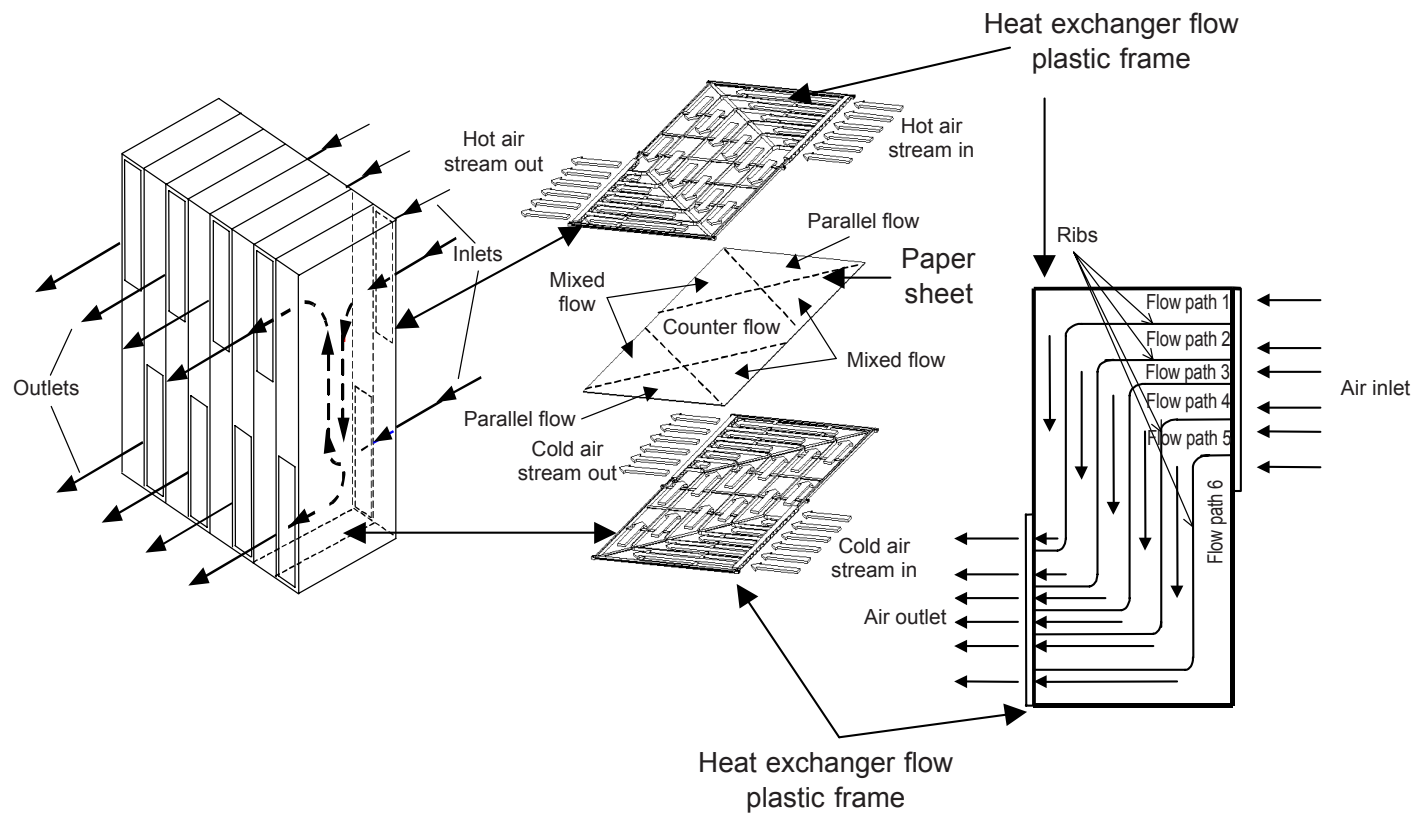

Figure $4 \mathrm{Z}$ type flow heat exchanger flow paths

inlets and outlets of the heat exchanger. The heat exchanger has an overall dimension of $0.6 \mathrm{~m} \times$ $0.72 \mathrm{~m} \times 0.3 \mathrm{~m}$. The heat exchanger is made up of 98 plastic frame flow passages with 49-inlet air passages in each of the air streams; the width of each flow passage is $6 \mathrm{~mm}$ and is designed with a ' $\mathrm{Z}$ ' shape flow configuration. The heat and moisture transfer surface is made of $78 \mu \mathrm{m}$ thick $45 \mathrm{gsm}$ Kraft paper with porosity of 0.0027 . The plastic frames are assembled together in an alternating pattern and the passage of the cold air stream is laterally inverted from the passage direction of the hot air stream (Figure 4).

Figure 5 shows the measured performance of the paper membrane heat exchanger. As can be seen, the sensible effectiveness is higher than the total and latent and total effectiveness, and the effectiveness decreases as the air flow rate increases, which is attributed to the air residence time in

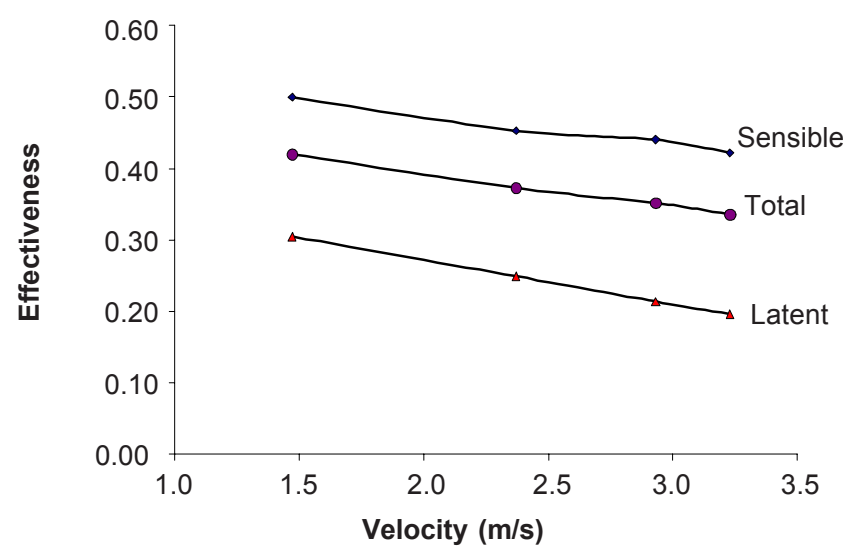

Figure 5 Paper heat exchanger measured sensible, latent and total effectiveness 
the heat exchanger. When the velocity is high, the residence time is short and the amount of heat and moisture transferred and the change in the enthalpy per kilogram of airflow will be less than when the air velocity is low.

\subsection{PERMEABILITY MEASUREMENT OF PAPER HEAT TRANSFER SURFACE}

Permeability measurements of the paper heat transfer surface were carried out according to the ASTM standard E 96-00 [5] requirements in order to study the paper membrane moisture transfer characteristic and to evaluate the paper moisture transfer resistance $\left(R_{\text {paper }}\right)$. This is needed to develop a model of the heat exchanger for numerical optimization of the design. This was achieved by conducting experiments to measure the amount of moisture transferred under controlled moisture conditions. The experimental rig consists of a plastic container, filled with distilled water with the paper material sealed to the rim. The container was placed on an electronic weighing scale to measure the amount of moisture transfer (Figure 6). A controlled environment is required to create a stable vapour pressure difference across the paper, thereby allowing a constant vapour transfer rate from the distilled water of higher vapour pressure and relative humidity of $100 \%$ to the controlled environment of less than $100 \%$. The whole experiment was contained in a glass tank to control the moisture conditions on the other side of the paper. The controlled humidity in the tank was achieved by mixing different types of salts with appropriate proportions of distilled water in the outer tank. The relative humidity and temperature in the glass tank are measured using humidity and temperature prob. In order to obtain the correct moisture transfer resistance, the humidity ratio difference between the paper surfaces in this experiment were similar to the humidity ratio difference between the hot and cold streams in the heat exchanger experiment. The humidity probe and the level of water in the plastic bowl were at equal distance from the paper surface as required by the ASTM standard E 96-00. The tank is covered and sealed with silicone and all the sides of the tank are insulated with polystyrene. The weight of the bowl, the relative humidity and temperature in the tank are recorded. Hence the moisture transfer flux through the paper $\left(\dot{\bar{m}}_{1}\right)$ is obtained.

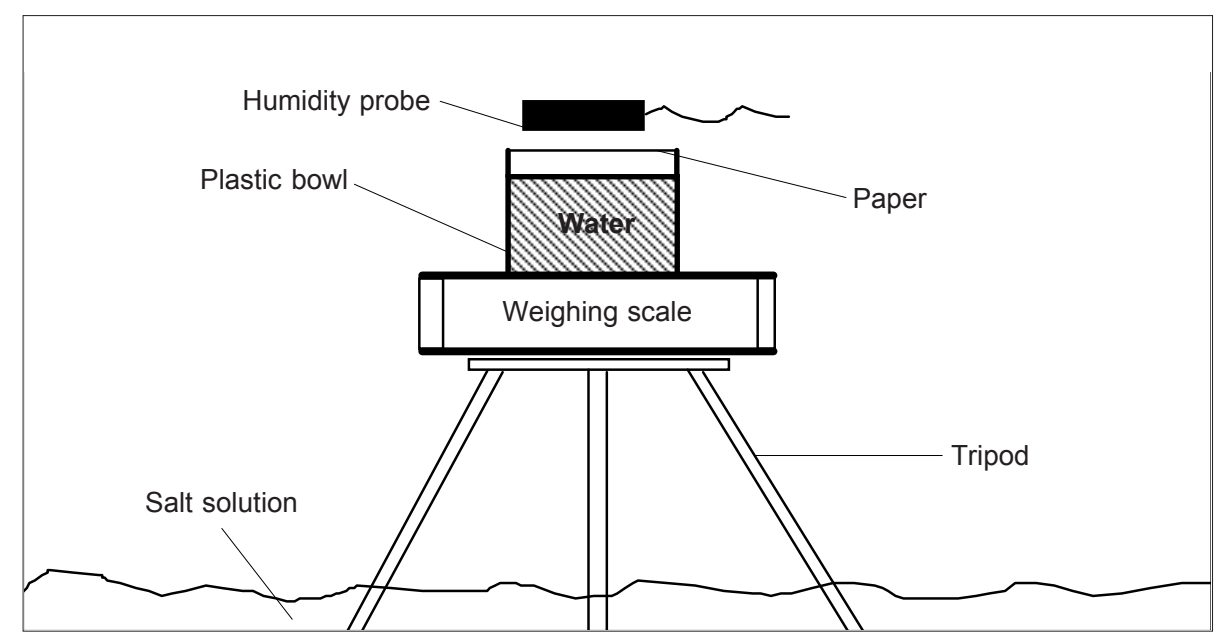

Figure 6 Schematic diagram of the permeability experiment 
Glass tank

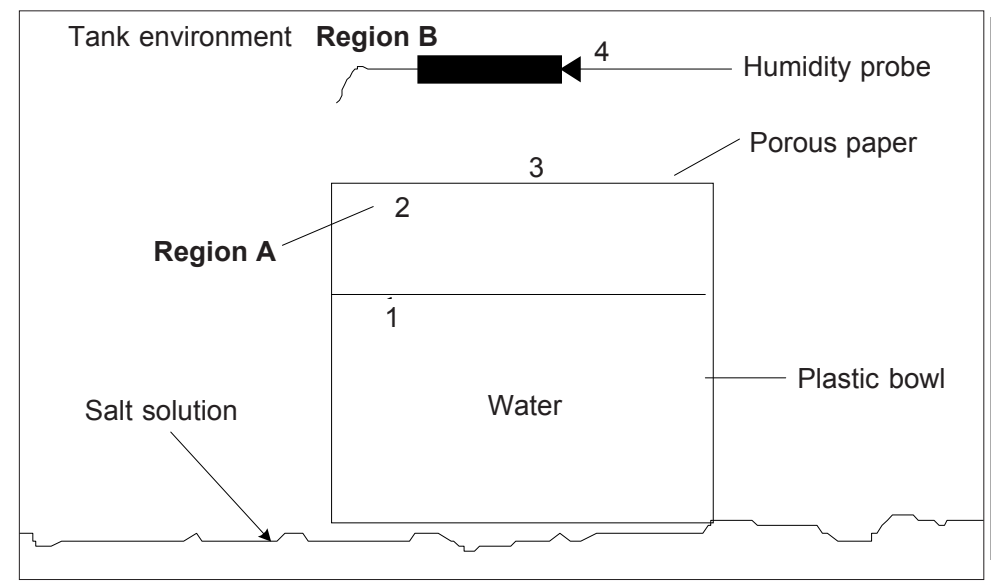

Figure 7 Moisture transfer measurement schematic diagram

As can be seen in Figure 7, the process of moisture diffusion is divided into 2 regions. In region A, the moisture is transferred from the water in the plastic bowl with $100 \%$ relative humidity to the lower surface of the paper. Then, the moisture will be transferred from lower surface of the porous paper to the upper surface, followed by moisture transfer from the upper surface to the controlled environment (region B).

In order to calculate the paper moisture transfer resistance, the relative humidity at the upper and lower surfaces of the paper has to be specified. This can be achieved by conducting a moisture transfer flux $\left(\dot{\bar{m}}_{2}\right)$ measurement on the same plastic bowl under the same experimental conditions but without placing the paper on the plastic bowl in order to obtain the air resistance in region $\mathrm{A}$ and B.

The air permeance is calculated as in the following:

$$
\operatorname{Per}_{\text {air }}=\frac{\dot{\bar{m}}_{2}}{P_{\text {Sat }}\left(R H_{1}-R_{4}\right)}
$$

The air moisture resistance can be expressed as:

$$
R_{\text {air }}=\frac{1}{\text { Per }_{\text {air }}}
$$

The distance between the water surface and lower surface of the paper at region A (point 1 to point 2) is equal to the distance between the humidity probe and upper surface of the paper at region $\mathrm{B}$ (point 3 to point 4). Whereas the paper is located at the middle distance between the water surface and the humidity probe, and the total air moisture resistance is measured from the water surface to the humidity probe (Equation (5)). Hence, the external air moisture resistance in regions A and B is taken to be half of the air moisture resistance $\left(R_{\text {air }}\right)$ measured without paper [6].

$$
R_{\text {air-regionA }}=R_{\text {air-region } B}=\frac{R_{\text {air }}}{2}
$$


Using the general form of permeance equation and substituting the measured moisture flux $\left(\dot{\bar{m}}_{1}\right)$ from the permeance experiment when paper was placed on the plastic bowl, the humidity on each side of the paper is obtained as follows:

$$
\begin{aligned}
& R H_{2}=R H_{1}-\frac{\dot{\bar{m}}_{1}}{\text { Per }_{\text {region } A} \times P_{\text {sat }}} \\
& R H_{3}=\frac{\dot{\bar{m}}_{1}}{\text { Per }_{\text {regionB }} \times P_{\text {sat }}}+R H_{4}
\end{aligned}
$$

Substituting Equations (5) and (6) in Equations (7) and (8):

$$
\begin{aligned}
& R H_{2}=R H_{1}-\frac{R_{\text {air-regionA }} \times \dot{\bar{m}}_{1}}{2 \times P_{\text {sat }}} \\
& R H_{3}=\frac{R_{\text {air-regionB } B} \times \dot{\bar{m}}_{1}}{2 \times P_{\text {sat }}}+R H_{4}
\end{aligned}
$$

where $\mathrm{RH}_{2}$ and $\mathrm{RH}_{3}$ represent the relative humidity on the lower and upper surface of the paper respectively (Figure 7).

From Equations (9) and (10) with the tank measured temperature, the humidity ratios on each side of the paper are obtained from the psychometric chart.

\subsection{MATHEMATICAL MODEL}

Using mathematical modelling is a way of predicting what would happen if some of the heat exchanger design and material characteristics were changed. Two mathematical models were developed to account for the heat and moisture transfer.

\subsection{Sensible Heat Transfer Model}

A mathematical model was developed using Nusselt $(\mathrm{Nu})$ correlation. In turbulent flow (Re>2000), the following Nusselt correlation is used [7]:

$$
N u=0.036 \operatorname{Re}^{0.8} \operatorname{Pr}^{\frac{1}{3}}\left(\frac{d_{h y}}{L}\right)^{0.055}
$$

Reynolds number of a flow is calculated as:

$$
\operatorname{Re}=\frac{V d_{h y}}{v}
$$

and the convective heat transfer coefficient $\left(h_{\text {heat }}\right)$ is calculated from the Nusselt number:

$$
N u=\frac{H_{h e a t} d_{h y}}{\lambda}
$$


The total number of transfer units is expressed as in the following:

$$
N T U_{s}=\frac{A_{h t} U_{s}}{C_{\min }}
$$

where the heat capacity of the stream is

$$
C=\dot{m} C_{p}
$$

The general form of overall heat transfer coefficient, $U_{s}$, is

$$
U_{s}=\left[\frac{1}{h_{h, \text { heat }}}+\frac{\delta}{k_{\text {ther }}}+\frac{1}{h_{c, \text { heat }}}\right]
$$

It can be seen from Equation (16) that there are three terms that contribute to the total heat transfer coefficient. The term in the middle is the thermal resistance of the $45 \mathrm{gsm}$ paper film, which represent the conduction heat transfer resistance and is a function of the material type and thickness. This term is very small $\left(6.5 \times 10^{-4} \mathrm{~m}^{2} \mathrm{~K} / \mathrm{W}\right)$ due to the small thickness of the paper sheet $(78 \mu \mathrm{m}$ thick). The other two terms are the convective heat transfer resistance terms, which contribute the largest portion of the total heat transfer resistance $\left(U_{s}\right)$.

From the calculated values of the total number of transfer units and the ratio of the minimum heat capacity $\left(C_{\min }\right)$ to the maximum heat capacity $\left(C_{\max }\right)$ of the two air streams, the sensible effectiveness is obtained. The heat exchanger flow configuration is a combination of counter flow, cross flow and parallel flow. Thus, the effectiveness of each flow region is evaluated and the overall effectiveness is determined from the area ratio of each flow region (Figure 8).

The effectiveness correlation for a counter-flow arrangement is

$$
\varepsilon_{s, \text { counter }}=\frac{1-\exp \left[-N T U\left(1-\frac{C_{\min }}{C_{\max }}\right)\right]}{1-\left(\frac{C_{\min }}{C_{\max }}\right) \exp \left[-N T U\left(1-\frac{C_{\min }}{C_{\max }}\right)\right]}
$$

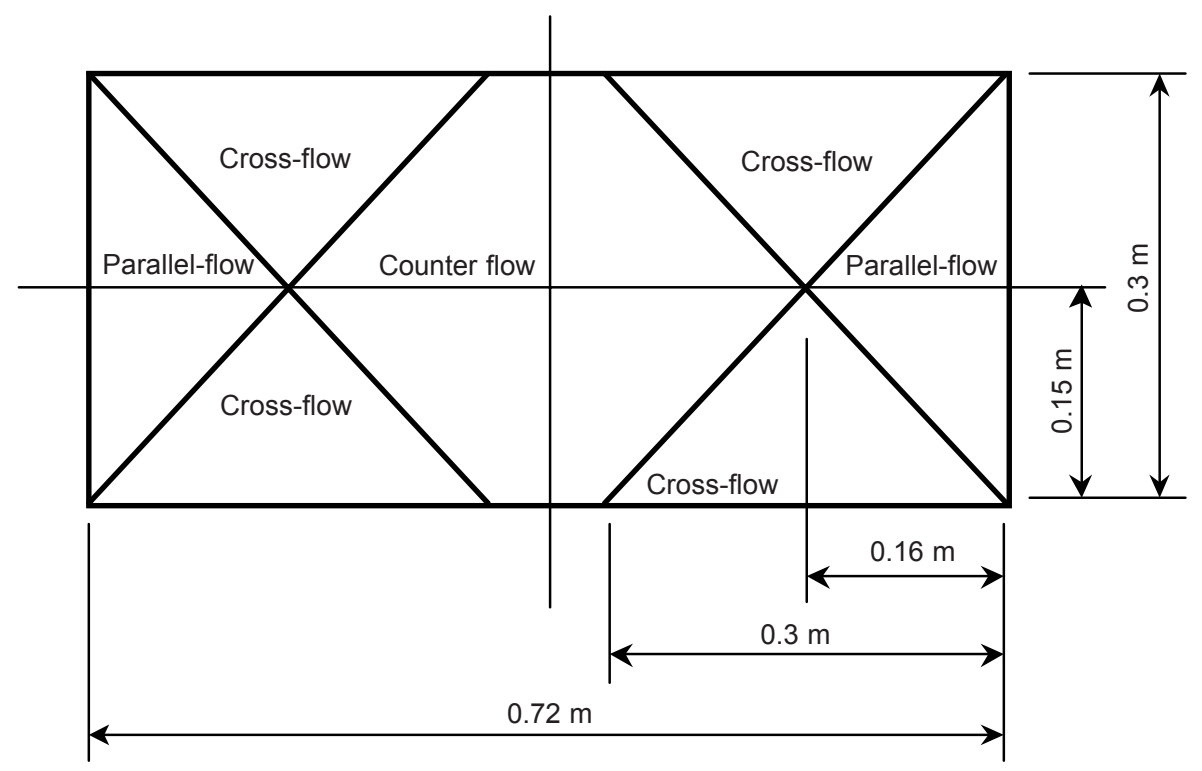

Figure 8 Heat exchanger flow arrangement 
The sensible effectiveness for a cross-flow arrangement is expressed as

$$
\varepsilon_{s, \text { cross }}=1-\exp \left\{\frac{N T U_{s}^{0.22}}{\frac{C_{\min }}{C_{\max }}}\left[\exp \left(-\frac{C_{\min }}{C_{\max }} N T U_{s}^{0.78}\right)-1\right]\right\}
$$

and the sensible effectiveness for a parallel arrangement is

$$
\varepsilon_{s, \text { parallel }}=\frac{1-\exp \left[-N T U_{s}\left(1+\frac{C_{\min }}{C_{\max }}\right)\right]}{\left(1+\frac{C_{\min }}{C_{\max }}\right)}
$$

The combined sensible effectiveness of the heat exchanger is obtained by combining Equations (17) to $(19)$ :

$$
\varepsilon_{s, \text { combined }}=\left(\frac{A_{\text {counter }}}{A_{h t}}\right) \varepsilon_{s, \text { counter }}+\left(\frac{A_{\text {cross }}}{A_{h t}}\right) \varepsilon_{s, \text { cross }}+\left(\frac{A_{\text {parallel }}}{A_{h t}}\right) \varepsilon_{s, \text { parallel }}
$$

\subsection{Latent Mathematical Model}

In this model, mass transfer is taken into consideration which requires developing a mass transfer model that accounts for the moisture transfer across the membrane. The model used is as in the following:

The convective mass transfer coefficient can be described by the Sherwood number (Sh) which is represented by:

$$
S h=\frac{h_{m a s s} d_{h y}}{D_{v a}}
$$

Using the Chilton-Colburn analogy [8],

$$
S h=N u L e^{-\frac{1}{3}}
$$

where $L e$ : Lewis number. By substituting Equations (13) and (21) into Equation (22), the convective mass transfer can be represented as follows:

$$
h_{\text {mass }}=\frac{h_{\text {heat }}}{C_{p a}} L e^{-\frac{1}{3}}
$$

For both ventilation air and vapour mixture, the Lewis number $(L e)$ varies between 1.19 and 1.22 [7]. In this model, it is assumed that Lewis number is equal to 1.2. To calculate the latent paper heat exchanger effectiveness, where the latent total number of transfer units $\left(N T U_{L}\right)$ is calculated based on the following:

$$
N T U_{L}=\frac{A_{h t} U_{L}}{\dot{m}_{\min }}
$$


The mass transfer coefficient $\left(U_{L}\right)$ is expressed as in the following:

$$
U_{L}=\left[\frac{1}{h_{h, \text { mass }}}+R_{\text {paper }}+\frac{1}{h_{c, \text { mass }}}\right]^{-1}
$$

Equation (25) consists of three terms, the term in the middle is the moisture resistance $\left(R_{\text {paper }}\right)$ of the porous paper and the other two terms are the convective mass transfer resistance of each flow stream. The resistance $\left(R_{\text {paper }}\right)$ is calculated from the measured moisture transfer flux and the humidity ratio on the upper and lower surfaces of the paper is obtained from the permeability experiment. The paper mass transfer resistance is calculated as follows:

$$
\dot{\bar{m}}_{1}=\frac{\left(\omega_{2}-\omega_{3}\right)}{R_{\text {paper }}}
$$

From the above equation, $R_{\text {paper }}$ is found to be $76 \mathrm{~m}^{2} \mathrm{~s} / \mathrm{kg}$ for $45 \mathrm{gsm}$ Kraft paper. In the latent heat exchanger, the moisture resistance $\left(R_{\text {paper }}\right)$ of the porous paper represents $43 \%$ of the total latent mass transfer resistance $\left(U_{L}\right)$. Thus, the paper moisture resistance of the paper membrane will have a significant effect on the overall latent effectiveness.

By substituting the value of $\left(R_{\text {paper }}\right)$ obtained from Equation (26) into Equation (25), the latent $N T U_{L}$ value is calculated. Analogues to the sensible effectiveness, the latent effectiveness in each flow region is calculated using the following expression [9]:

$$
\begin{gathered}
\varepsilon_{L, \text { counter }}=\frac{1-\exp \left[-N T U_{L}\left(1-\frac{\dot{m}_{\min }}{\dot{m}_{\max }}\right)\right]}{1-\left(\frac{\dot{m}_{\min }}{\dot{m}_{\max }}\right) \exp \left[-N T U_{L}\left(1-\frac{\dot{m}_{\min }}{\dot{m}_{\max }}\right)\right]} \\
\varepsilon_{L, \text { cross }}=1-\exp \left\{\frac{N T U_{L}^{0.22}}{\left.\frac{\dot{m}_{\min }}{\dot{m}_{\max }}\left[\exp \left(-\frac{\dot{m}_{\min }}{\dot{m}_{\max }} N T U_{L}^{0.78}\right)-1\right]\right\}}\right. \\
\varepsilon_{L, \text { parallel }}=\frac{1-\exp \left[-N T U_{L}\left(1+\frac{\dot{m}_{\min }}{\dot{m}_{\max }}\right)\right]}{\left(1+\frac{\dot{m}_{\min }}{\dot{m}_{\max }}\right)}
\end{gathered}
$$

The overall latent effectiveness accounting for the different flow regions is:

$$
\varepsilon_{L, \text { combined }}=\left(\frac{A_{\text {counter }}}{A_{h t}}\right) \varepsilon_{L, \text { counter }}+\left(\frac{A_{\text {cross }}}{A_{h t}}\right) \varepsilon_{L, \text { cross }}+\left(\frac{A_{\text {parallel }}}{A_{h t}}\right) \varepsilon_{L, \text { parallel }}
$$

Figure 9 shows the prediction of this mathematical model was found to be reasonably consistent with the experimental results. Therefore, the mathematical model can confidently be used as a design aid to predict the heat exchanger performance when the design parameters and material characteristics are changed. Figure 9 shows that the sensible effectiveness is higher than the latent effectiveness and that is attributed to the high moisture resistance of the paper membrane. 


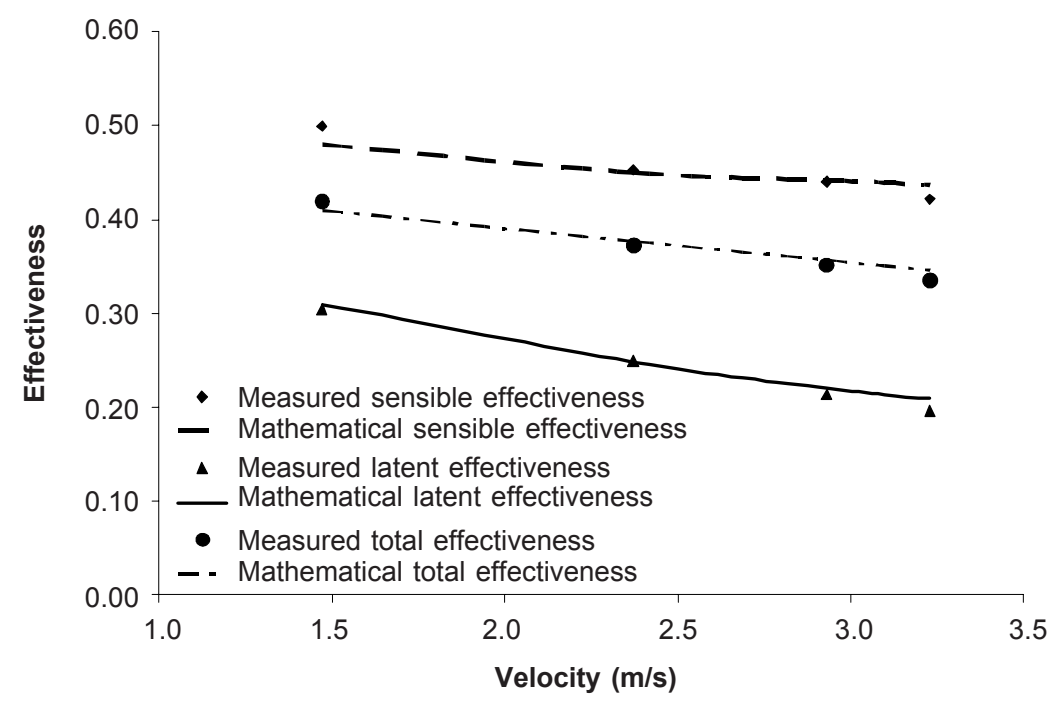

Figure 9 Experimental and predicted sensible, latent and total effectiveness

Using this model to predict the heat exchanger performance when the plastic frame flow path inlet width decreased from 6 to $4 \mathrm{~mm}$ shows a 9\% increase in both sensible and latent effectiveness values which will lead to a substantial increase in the heat exchanger performance (Figure 10).

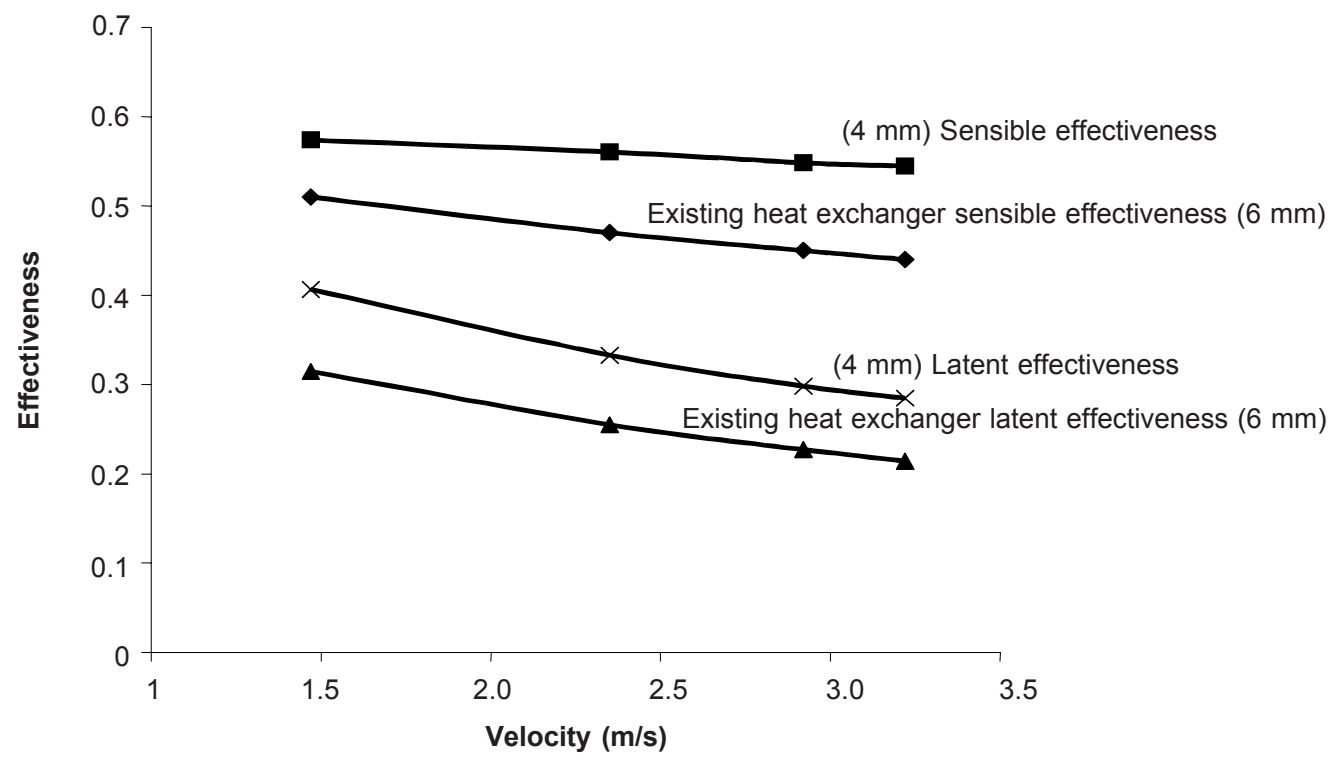

Figure 10 Existing heat exchanger effectiveness with $6 \mathrm{~mm}$ width flow path and $4 \mathrm{~mm}$ width flow path heat exchanger predicted effectiveness 


\subsection{ENERGY RECOVERY}

The performance of an air conditioner utilizing paper heat exchanger is studied by incorporating the heat exchanger in a conventional air conditioning cycle using the HPRate air conditioning performance rating software. This software evaluates the performance of a typical vapour compression air conditioning cycle using R22 refrigerant. The evaporator coil frontal area is $0.5 \mathrm{~m}^{2}$ and the condenser coil frontal area is $0.6 \mathrm{~m}^{2}$. The air flow rate supplied to the evaporator is 1000 liter/s. By determining the air conditions entering the evaporator and condenser, HPRate is able to predict the steady state heating and cooling performance of vapour compression, electrically driven, air-to-air reverse cycle heat pumps [10]. Two different systems are investigated using HPRate as in the following:

a) Air conditioning system using paper heat exchanger (100\% fresh air).

In this system, $100 \%$ fresh air is supplied to one of the heat exchanger streams. On the other stream, the room conditioned air is supplied at $24^{\circ} \mathrm{C}$ dry bulb temperature and $50 \%$ relative humidity. The heat exchanger outlet air conditions are calculated from the effectiveness equations using spreadsheet and exported to the evaporator and condenser units in HPRate Software (Figure 11). The performance of this system is studied under weather conditions similar to the tropical weather conditions in Malaysia and Darwin with $32^{\circ} \mathrm{C}$ dry bulb temperature and $80 \%$ relative humidity. With this air conditions, the relative heat exchanger outlet air conditions are exported to HPRate.

As can be seen in Figure 11 for applications of pre-conditioning of make-up air for building ventilation, the paper surface has the advantage of also dehumidifying the incoming air, where the fresh air moisture content has decreased before it enters the evaporator.

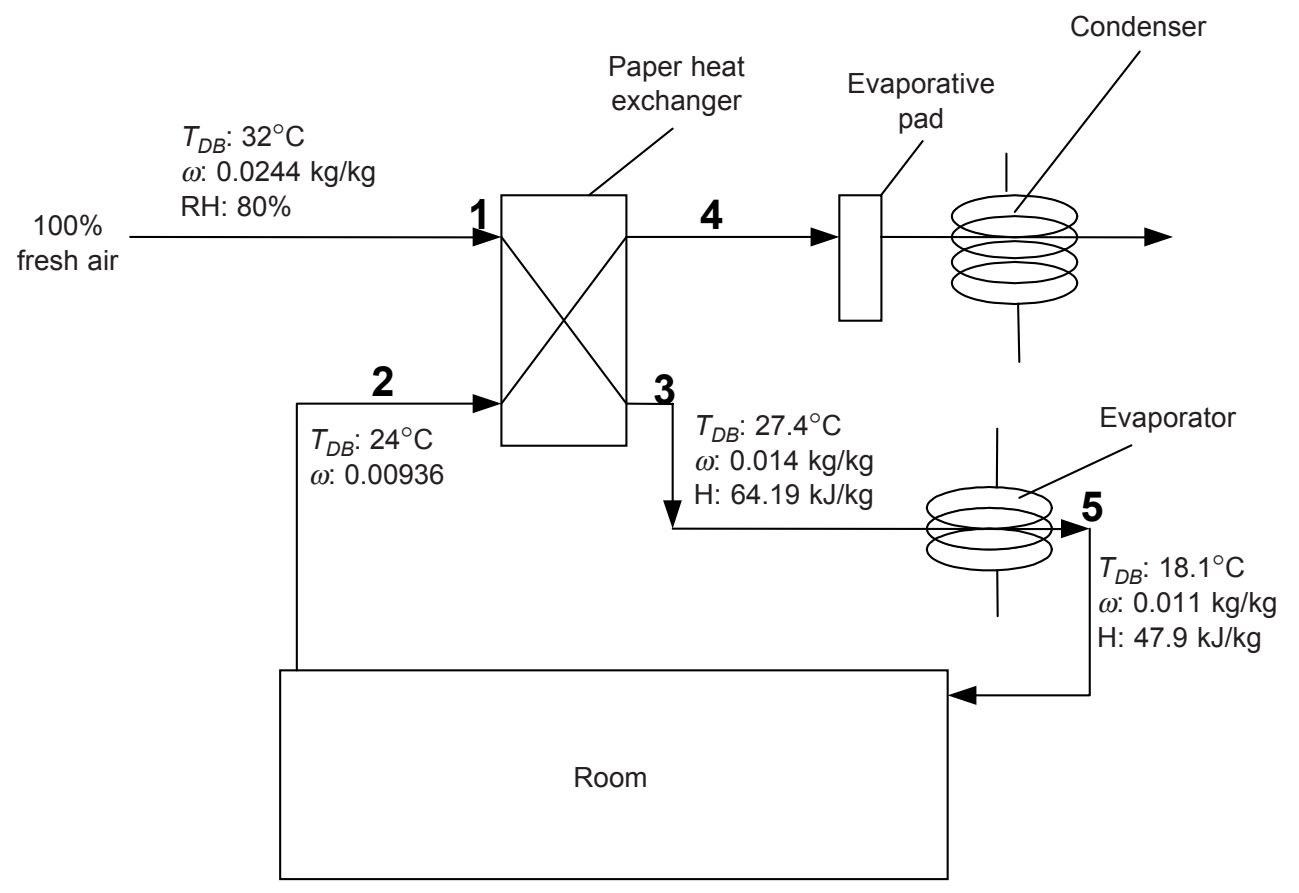

Figure 11 Schematic diagram of the air conditioning system with paper heat exchanger 
The air conditioner cooling load is expressed as in the following. The sensible cooling load is represented by:

$$
Q_{\text {Sensible-load }}=\dot{m} C p_{\text {air }}\left(T_{1}-T_{5}\right)
$$

analogous to the sensible load, the latent load is

$$
Q_{\text {Latent-load }}=\dot{m} h_{f g}\left(\omega_{1}-\omega_{5}\right)
$$

and the total cooling load is obtained as follows:

$$
Q_{\text {Total-load }}=\dot{m}\left(H_{1}-H_{5}\right)
$$

b) Conventional air conditioning system.

In this system, the evaporator supplied air is a mixture of $70 \%$ room exhaust air and $30 \%$ ambient fresh air (Figure 12). The room exhaust air condition is $24^{\circ} \mathrm{C}$ dry bulb temperature and $50 \%$ relative humidity. The performance of this system is studied under the same weather condition used in the paper heat exchanger system.

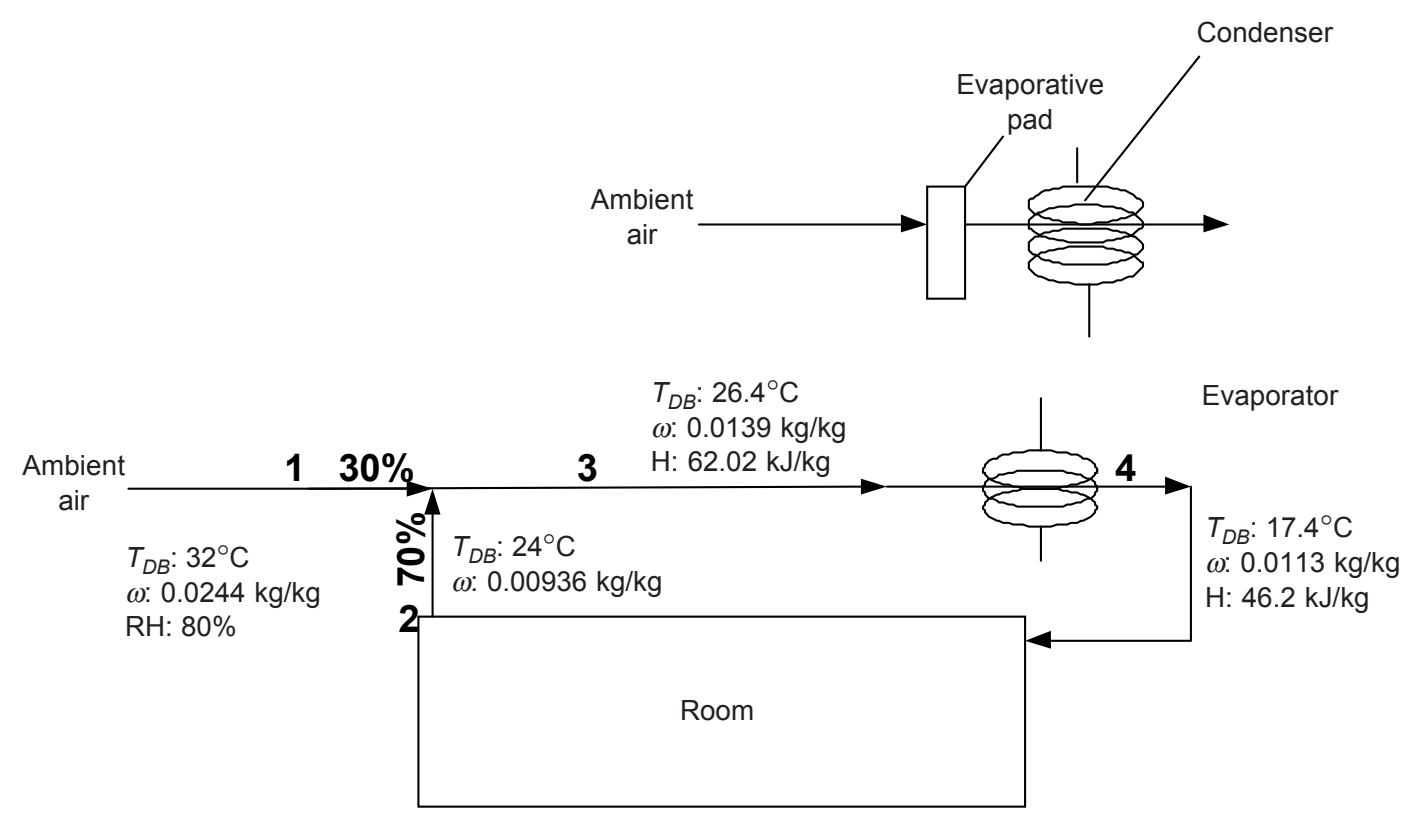

Figure 12 Schematic diagram of a conventional air conditioning system

Similar to the paper heat exchanger, the air conditioner cooling load is calculated as follows:

$$
\begin{aligned}
Q_{\text {Sensible-load }} & =\dot{m} C p_{\text {air }}\left(T_{1}-T_{4}\right) \\
Q_{\text {Latent-load }} & =\dot{m} h_{f g}\left(\omega_{1}-\omega_{4}\right) \\
Q_{\text {Total-load }} & =\dot{m}\left(H_{1}-H_{4}\right)
\end{aligned}
$$


Table 1 Air conditioning system performance

\begin{tabular}{lcccccc}
\hline System & $\begin{array}{c}\text { Sensible } \\
\text { cooling } \\
\text { load } \\
\mathbf{k W}\end{array}$ & $\begin{array}{c}\text { Latent } \\
\text { cooling } \\
\text { load } \\
\mathbf{k W}\end{array}$ & $\begin{array}{c}\text { Total } \\
\text { cooling } \\
\text { load } \\
\mathbf{k W}\end{array}$ & $\begin{array}{c}\mathbf{A} / \mathbf{C} \\
\text { cooling } \\
\text { capacity } \\
\mathbf{k W}\end{array}$ & $\begin{array}{c}\text { Supplied } \\
\text { air } \\
\text { temperature } \\
\text { to the room }\end{array}$ & $\begin{array}{c}\mathbf{A} \mathbf{C} \\
\mathbf{C O P}\end{array}$ \\
\hline $\begin{array}{l}\text { Membrane } \\
\text { heat } \\
\text { exchanger }\end{array}$ & 11.8 & 9.2 & 20 & 18.6 & 18.1 & 3.76 \\
$\begin{array}{l}\text { Conventional } \\
\text { (Air mixing) }\end{array}$ & 11.9 & 8 & 19.9 & 17.7 & 17.7 & 3.45 \\
\hline
\end{tabular}

Table 1 shows that the air conditioner coefficient of performance (COP) and cooling capacities recorded the highest values when paper heat exchanger is utilized, where the COP and the cooling capacity values increased by $8 \%$ and $5 \%$ respectively in comparison with the conventional air conditioning system. Table 1 also shows that the air conditioner cooling loads and the conditioned air temperature delivered to the room when paper heat exchanger is used is almost similar to the cooling load and air temperature delivered when the conventional air conditioner is used. This means when the paper heat exchanger is utilized, the air conditioner performance and cooling capacity has increased in comparison with the conventional air conditioner. Thereby, using the paper heat exchanger is more favourable because it improves the air conditioner performance and capacity and maintains the same cooling load and delivers almost the same air temperature to the room with the advantage of providing $100 \%$ fresh air, and that will improve the indoor air quality.

\subsection{CONCLUSION}

The performance of a latent energy heat exchanger using a paper heat exchange surface was evaluated experimentally. The results are represented in terms of sensible and latent effectiveness. The results show that the sensible effectiveness is higher than the latent effectiveness due to the high moisture resistance of the paper membrane. A mathematical model of the sensible and latent characteristics of the paper membrane heat exchanger was developed and validated against the measured results. The paper moisture transfer resistance was determined using permeability measurement. System analysis using HPRate software which models a typical vapour compression air conditioning cycle shows, when the paper heat exchanger is used in this cycle in a humid climate similar to the weather in Malaysia and Darwin, the air conditioner coefficient of performance and cooling capacity has increased in comparison with the conventional air conditioning system.

\section{ACKNOWLEDGEMENTS}

The authors would like to acknowledge the financial support received from the Australian Research Council and Air-Change Pty Ltd. 


\section{NOMENCLATURE}

A area of heat/moisture transfer $\left(\mathrm{m}^{2}\right)$

$C_{p} \quad$ specific heat capacity $(\mathrm{kJ} / \mathrm{kgK})$

$C$ heat capacity rate $(\mathrm{W} / \mathrm{K})$

$D_{v a} \quad$ vapour air diffusivity $\left(\mathrm{m}^{2} / \mathrm{s}\right)$

$d_{h y} \quad$ hydraulic diameter $(\mathrm{m})$

$h \quad$ convective heat/mass transfer coefficient. For heat transfer $\left(\mathrm{W} / \mathrm{m}^{2} \mathrm{~K}\right)$ and for mass transfer $\left(\mathrm{kg} / \mathrm{m}^{2} \mathrm{~s}\right)$.

$H \quad$ enthalpy $(\mathrm{kJ} / \mathrm{kg})$

$h_{f g} \quad$ enthalpy of evaporation $(\mathrm{kJ} / \mathrm{kg})$

$k_{\text {ther }} \quad$ thermal conductivity of paper film $(\mathrm{W} / \mathrm{mK})$

$L \quad$ entry length of air streams (m)

$\dot{m} \quad$ mass flow rate $(\mathrm{kg} / \mathrm{s})$

$\dot{\bar{m}} \quad$ moisture transfer flux $\left(\mathrm{kg} / \mathrm{m}^{2} \mathrm{~s}\right)$

$P_{\text {sat }} \quad$ saturation pressure $(\mathrm{Pa})$

Per permeance $\left(\mathrm{kg} / \mathrm{m}^{2} \mathrm{~s} \mathrm{~Pa}\right)$

$R_{\text {paper }} \quad$ paper moisture transfer resistance $\left(\mathrm{m}^{2} \mathrm{~s} / \mathrm{kg}\right)$

$R_{\text {air }} \quad$ air moisture resistance $\mathrm{m}^{2} \mathrm{~s} \mathrm{~Pa} / \mathrm{kg}$

RH relative humidity

$T$ temperature $\left({ }^{\circ} \mathrm{C}\right)$

$U \quad$ total heat/mass transfer coefficient for heat transfer $\left(\mathrm{W} / \mathrm{m}^{2} \mathrm{~K}\right)$ and for mass transfer $\left(\mathrm{kg} / \mathrm{m}^{2} \mathrm{~s}\right)$.

$V \quad$ velocity of air stream $(\mathrm{m} / \mathrm{s})$

\section{Greek Letters}

$\varepsilon_{S} \quad$ sensible effectiveness

$\varepsilon_{l} \quad$ latent effectiveness

$\varepsilon_{t} \quad$ total effectiveness

$\rho \quad$ air density $\left(\mathrm{kg} / \mathrm{m}^{3}\right)$

$\lambda$ thermal conductivity of air $(\mathrm{W} / \mathrm{mK})$

$\delta \quad$ thickness of paper film (m)

$\omega \quad$ humidity ratio ( $\mathrm{kg} / \mathrm{kg}$ dry air)

\section{Subscripts}

c cold air stream

h hot air stream

i inlet

L latent

o outlet

\section{REFERENCES}

[1] Fisk, W. J. and I. Turiel. 1983. Residential Air-to-Air Heat Exchangers: Performance, Energy Savings, and Economics. Energy and Buildings. 5: 197-211. 
[2] Dhital, P., R. W. Besant, and G. J. Schoenau. 1995. Integrating Run-around Heat Exchanger Systems into the Design of Large Office Buildings. ASHRAE Transactions. 101(2): 979-991.

[3] Zhang, L. Z. and Y. Jiang. 1999. Heat and Mass Transfer in a Membrane-Based Energy Recovery Ventilator. J. Membr. Sci. 163: 29-38.

[4] Niu, J. L. and L. Z. Zhang. 2001. Membrane-Based Enthalpy Exchanger: Material Consideration and Clarification of Moisture Resistance. J. Membr. Sci. 189: 179-191.

[5] ASTM: E96. 2000. American Standard Test Methods for Water Vapor Transmission of Materials. American Society for Testing and Materials. 842-849.

[6] Fanney, A. H., W. C. Thomas, D. M. Burch, and L. R. Mathena. 1991. Measurements of Moisture Diffusion in Building Materials. ASHRAE Transactions. 97: 99-113.

[7] Holman, J. P. 1992. Heat Transfer. New York: McGraw-Hill Inc.

[8] Kays, W. M. and M. E. Crawford. 2005. Convective Heat and Mass Transfer. $4^{\text {th }}$ Edition. Singapore: McGraw-Hill International Edition.

[9] Niu, J. L. and L. Z. Zhang. 2002. Potential Energy Savings for Conditioning Fresh Air with Membrane-Based Energy Recovery Ventilator. ASHRAE Transactions. 108: 54-63.

[10] Morrison, G. L. 2004. Air Conditioner Performance Rating. Asia Pacific Economic Co-operation Conference. Air Conditioning - The Next 5 Years. Sydney. 